\title{
Patterns of Cranial Trauma at the Akers Site (34LF32) of Southeastern Oklahoma
}

Simone Rowe

Oklahoma State University

Follow this and additional works at: https://scholarworks.sfasu.edu/ita

Part of the American Material Culture Commons, Archaeological Anthropology Commons, Environmental Studies Commons, Other American Studies Commons, Other Arts and Humanities Commons, Other History of Art, Architecture, and Archaeology Commons, and the United States History Commons

Tell us how this article helped you.

This Article is brought to you for free and open access by the Center for Regional Heritage Research at SFA ScholarWorks. It has been accepted for inclusion in Index of Texas Archaeology: Open Access Gray Literature from the Lone Star State by an authorized editor of SFA ScholarWorks. For more information, please contact cdsscholarworks@sfasu.edu. 


\section{Patterns of Cranial Trauma at the Akers Site (34LF32) of Southeastern Oklahoma Creative Commons License (c) $($ ) $(9)$}

This work is licensed under a Creative Commons Attribution-NonCommercial 4.0 International License 


\title{
Patterns of Cranial Trauma at the Akers Site (34LF32) of Southeastern Oklahoma
}

\author{
Simone Rowe \\ Oklahoma State University
}

Previous work at Wister Valley Fourche Maline sites in southeastern Oklahoma has concluded that the area was a contested landscape with extensive feuding, resulting trophy-taking behavior, and mass burials. Preliminary paleopathological work at the Akers site (34Lf32) suggested that there may have been a high percentage of broken bones, however complete analyses had not been completed. New paleopathological work at the Akers site indicates that 35 percent of the adults buried there had at least one fractured bone at time of death. Furthermore, adult females were more likely to have lower limb fractures and multiple fractures, suggesting different patterns of stress and/or violence for at least some of the adult female population.

\section{Introduction}

Previous work at Wister Valley Fourche Maline sites in southeastern Oklahoma has concluded that the area was a contested landscape with extensive feuding, resulting in trophy-taking behavior, burials with embedded projectile points, and multiple mass burials (Rowe 2014). This study examines patterns of interpersonal violence by examining cranial trauma at Akers (34Lf32), a Wister Valley Fourche Maline site. Cranial injuries are often used by bioarchaeologists as a gauge of interpersonal violence (Bogonofsky 2011). Walker (1989), for instance, was able to demonstrate significantly different levels of cranial trauma between different populations and to also show an increase in cranial trauma through time. Sex based differences in cranial trauma have also been demonstrated in both North American (Martin 1997) and South American (Tung 2007) archeological populations. Patterns of cranial trauma at the Akers site suggest that although males and females were equally likely to suffer from cranial trauma, there were differences in the patterning and type of cranial injury, suggesting that males and females were at risk for different types of interpersonal violence.

\section{Background: The Wister Valley, Fourche Maline, and the Akers Site (34Lf32)}

Between 1938 and 1941, the Works Progress Administration (WPA) conducted 24 major archeological digs in the Wister Valley (the northernmost valley of the Ouachita Mountains) of southeastern Oklahoma (Rogers 1978). Wister Valley (sometimes called Fourche Machine Valley) is defined by Fourche Maline Creek, which runs in a west to east direction before it eventually merges with the Poteau River, and then turns north to join the Arkansas River (Figure 1). The Wister area is part of the "Trans-
Mississippi South," defined by Schambach (1998) as the region west of the Lower Mississippi Valley and east of the Plains, bounded to the north by the Ozark Plateau and to the south by the Gulf Coast swamps. This area is an upland (rather than lowland) forest, which may have facilitated different adaptations and thus different artifact assemblages from more familiar eastern Woodland sites (Schambach 1982:136).

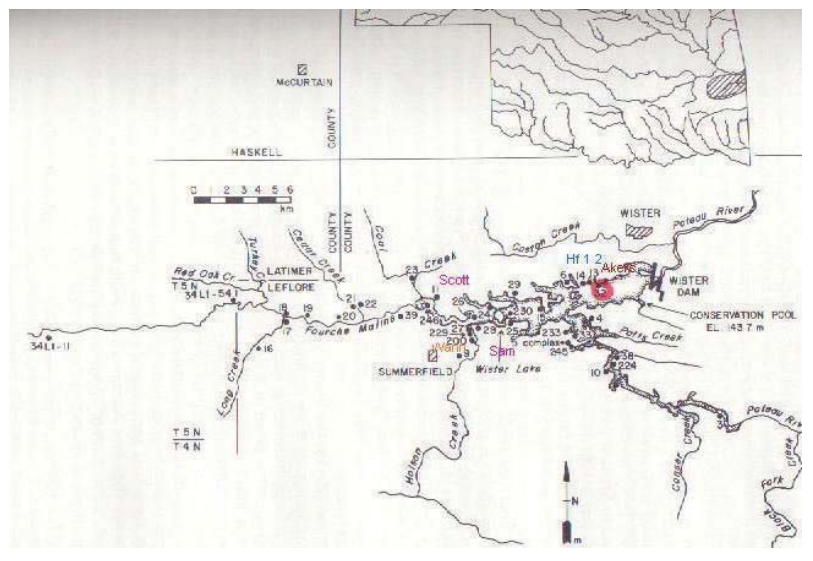

Figure 1. The Wister Area with several Fourche Maline sites, including Akers (34LF32).

Most of the Wister area sites were small mounds with dark soils that lacked stratigraphy. Even though many of the mounds contained burials, the confusing mix of artifacts led the WPA to call them midden mounds, and they were designated as Fourche Maline, after the creek (Newkumet 1941). The term Fourche Maline has since been used to denote a focus (as defined by McKern 1939), an archeological area, a site component, a site complex, a site type, and most commonly, a local cultural phase (as defined by Willey and Phillips 1958). Fourche Maline is thus a problematic label, spanning some 600 years (A.D. 300 to 900) or the late Woodland (Galm 1984). This lack of temporality, has led some researchers to disregard data from these sites. However, while it is true 
that fine temporal divisions cannot be gleaned from these sites, they nevertheless can provide general information about long term patterns. A more thorough examination of the concept of Fourche Maline within the context of North American and Caddo archeology can be found in Rowe 2014 (40-49).

The Akers site is the eastern-most site excavated by the WPA in the Wister area (see Figure 1). Although the site is now under the waters of Wister Reservoir, it was completely excavated in 1941 by the WPA under the supervision of Dr. Forest Clements of The University of Oklahoma, and field supervisor Phil Newkumet (Rogers 1978:2). Described as a long, low mound with no visible stratigraphy (Figure 2 ), the site was excavated in 1-foot levels, as was common at the time (Newkumet 1941). Over 200 individuals and thousands of artifacts were excavated and stored at the Stovall Museum, now the Sam Noble Oklahoma Museum of Natural History (SNOMNH), in Norman, Oklahoma.

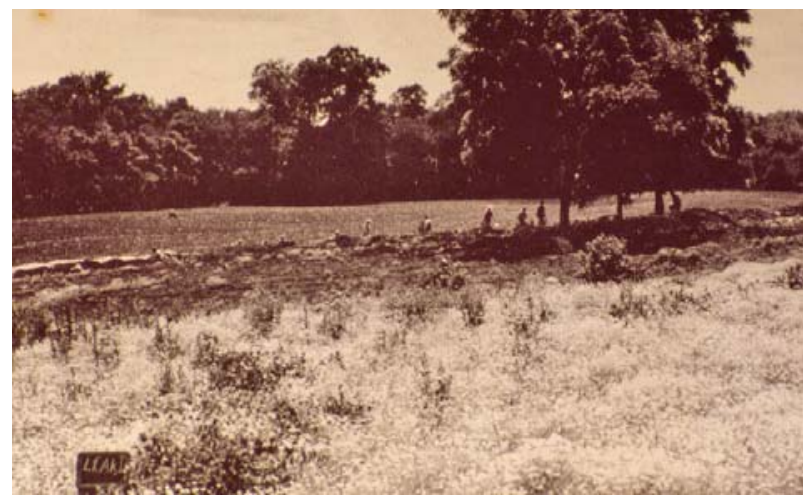

Figure 2. The Akers site (34Lf32), during exaction in 1941, photo courtesy SNOMNH.

Previous work at the Akers site demonstrated two striking observations. First, there were nearly twice as many adult female skeletons as adult male skeletons (Rowe 2009:52), and second, subadults showed high rates of skeletal lesions associated with nutritional deficiencies, particularly scurvy (Rowe 2009:75-81). Additionally, valley-wide archival research looking at 14 Fourche Maline Wister Area sites demonstrated that approximately 25 percent of excavated individuals were interred in a multiple burial (Rowe 2014:132). Multiple burials (i.e. burials with more than one individual) are considered "good evidence for intergroup conflict" (Milner 1999:9). Furthermore, burials in the Wister Valley fit the paradigm for feuding as described by Dye (2009), in that the burials demonstrate high rates of embedded projectile points, multiple mass burials, and individuals skulls, suggesting trophy-taking behavior. This study seeks to elucidate patterns of violence at these Wister Valley sites by examining the prevalence and pattern of cranial trauma from adult burials at the Akers site.

\section{Study Methodology and Population}

This study examines cranial injuries from the Akers site. In 2008 I requested and received permission from the Caddo Nation and the Wichita and Affiliated tribes to conduct non-destructive analysis of these burials. In 2009 I completed a basic paleodemography for the total burial population as well as paleopathology on the subadults, or children (Rowe 2009). Additional paleopathology on the adults was completed in 2014 (Rowe 2014).

The WPA reported that they excavated 168 burials containing 204 individuals, including 11 children (Newkumet 1941). A minimum of 227 individuals, including 33 subadults, were identified during laboratory analysis (Rowe 2009:50). Standard methods of aging and sexing the remains are detailed in Rowe 2009 and will not be repeated here.

The condition and completeness of the skeletal remains from the Akers site varied enormously. Not all the individuals that were aged and sexed for the 2009 study were used in the current study. For this current study, 97 of the best preserved adult crania from the Akers site were analyzed. Only individuals that could be confidently aged and sexed were selected.

All of the 97 individuals included in this study are aged as "Adult" (minimum 15 years skeletally). Due to general poor preservation and the inherent inaccuracies of aging adult skeletons, age categories are reported in very broad terms. Young Adults (YA) are 15-35 skeletal years, Middle Adults (MA) are 35-50 skeletal years, and Old Adults (OA) are 50+ skeletal years.

Due to both preservation issues and excavation damage, most of the Akers crania are missing the basicrania (underside of the skull) as well as their maxilla (upper jaws), making it impossible to detail facial fractures. I therefore concentrated on trauma to the calvarium (the "round" part of the skull). Additionally, the majority of crania exhibited at least some degree of cultural modification. While some of the modifications appear to have been passive modification from use of a cradle board, other individuals had evidence of active reshaping including changes to the frontal bone and with marks from pads and or bindings. Because multiple types of modification were observed in the Akers crania, a separate study will consider the types of modification and their cultural implications.

The skeletal remains were examined visually and under magnification of up to 40x using a binocular dissecting microscope. Additional imaging was via the macro lens of a 3.3 megapixel DSC-F505V Sony digital camera. 


\begin{tabular}{|c|c|c|c|c|c|c|}
\hline & \multicolumn{3}{|c|}{ YA 15 - 35 Years } & \multicolumn{3}{|c|}{ MA 35 - 50 Years } \\
\hline & + & $n$ & $f$ & + & $n$ & $f$ \\
\hline$M$ & 2 & 7 & 29 & 3 & 23 & 13 \\
\hline $\mathbf{F}$ & 5 & 29 & 17 & 5 & 18 & 28 \\
\hline$p$ values & & & $p=.6$ & & & $p=.4$ \\
\hline Total & 7 & 36 & 19 & 8 & 41 & 20 \\
\hline
\end{tabular}

\begin{tabular}{|r|r|r|}
\hline \multicolumn{3}{|c|}{ OA 50+ Years } \\
\hline$+\quad$ & $\mathrm{n}$ & \multicolumn{1}{|c|}{$f$} \\
\hline 0 & 10 & 0 \\
\hline 3 & 10 & 30 \\
\hline & & N/A \\
\hline 3 & 20 & 15 \\
\hline
\end{tabular}

\begin{tabular}{|r|r|r|}
\hline \multicolumn{3}{|c|}{ Total } \\
\hline$+\quad$ & N & $f$ \\
\hline 5 & 40 & 13 \\
\hline 15 & 57 & 23 \\
\hline & & $p=.3$ \\
\hline 18 & 97 & 19 \\
\hline
\end{tabular}

Table 1. Cranial trauma by age and sex.; $+=$ number of injuries; $n=$ sample size; $f=$ frequency

\section{Results}

A total of 97 adult crania were examined, and 21 traumatic wounds affecting 18 individuals were observed. Overall, 19 percent of the individuals included in the study had at least one traumatic cranial wound. Although females were nearly twice as likely to experience a skeletal cranial trauma as males ( $\mathrm{F}=23$ percent, $\mathrm{M}=13$ percent), this difference was not found to be statistically significant ( $p=.3$, Fisher's Exact Test, two-tailed probability). The number and frequency of cranial wounds by both sex and age, along with $\mathrm{p}$ values, are detailed in Table 1 .

The majority of cranial wounds were depressed fractures in various stages of healing. Depressed fractures to the skull are usually caused by blunt force trauma (BFT), such as a club to the head (Ortner 2003:121). Also present were sharp force trauma (SFT) in the form of projectile point wounds and cut marks. Each traumatic wound to the calvarium by burial, age group, sex, bone affected, trauma type, shape of wound, and healing status is presented in Table 2. Male cranial injuries are grouped first, followed by female cranial injuries, and BFTs are presented before SFTs.

Forty males were examined and five cranial wounds (13 percent of the male study population) were observed. These were all depressed fractures, or BFTs. Three of these wounds were to the frontal bone, and one of these frontal wounds appears to have been perimortem (without signs of healing). The two remaining wounds were to the back of the parietal bones, suggesting that the individual was hit from behind. The pattern of male cranial wounds is depicted in Figure 3. No cranial SFT wounds were observed in males and no males were observed to have more than one cranial wound. Additionally, only young adult and middle adult males were observed with cranial wounds. No older adult males $(50+$ years) were found with cranial wounds or trauma.

Females ( $N=57)$ were observed with 16 cranial wounds (23 percent of the female study population). Depressed fractures, or BFTs, accounted for 11 wounds, affecting nine females. Six of these wounds were to the frontal bone. The remaining five cranial BFT wounds were to the parietals. Three of these parietal wounds were to the back of the head, once again suggesting that the individuals were hit from behind. The pattern of female cranial BFT wounds is depicted in Figure 4. All of the BFT wounds were in various stages of healing, indicating

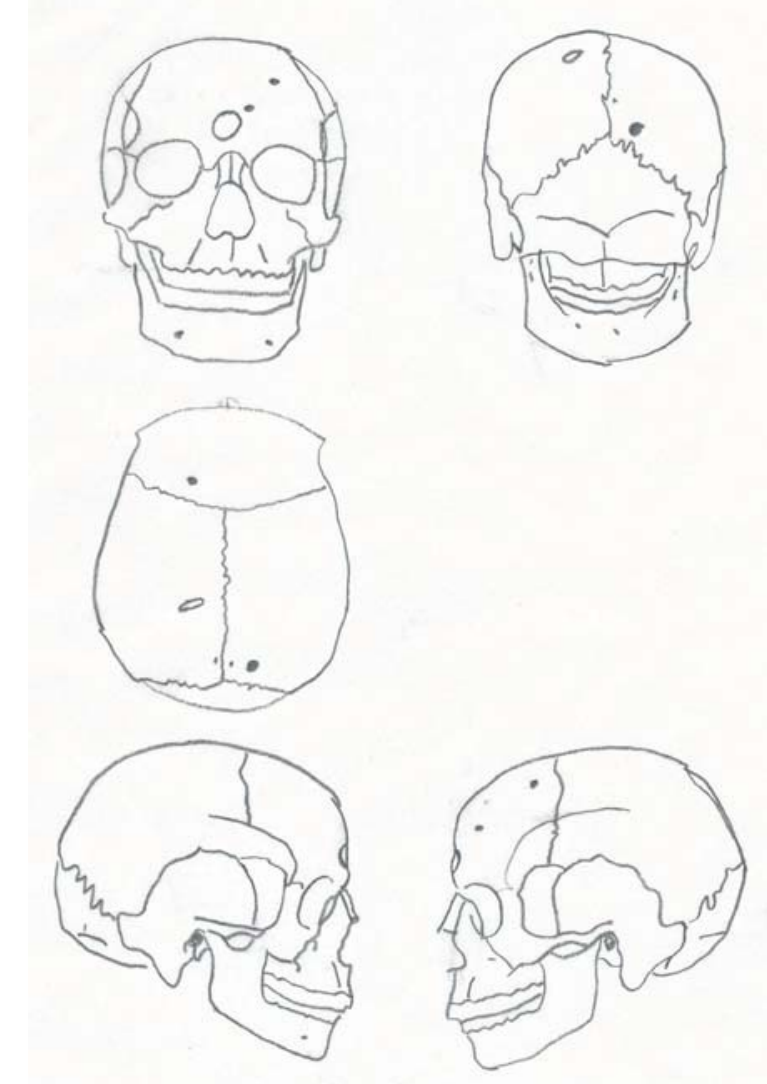

Figure 3. Male cranial blunt force trauma injuries.

that they did not directly contribute to death. Young middle and old adult females suffered from BFT cranial injuries.

Additionally, there were five penetrating, or SFT wounds, affecting five females. Four of these SFT wounds were to young adult females and one was to an old adult female. All of but one of the wounds showed no signs of healing, indicating that they were peri-mortem injuries. The pattern of female cranial SFT wounds is depicted in Figure 5. As can be seen, two of these wounds were to the right frontal bone, indicating a face to face encounter. One wound was to the back of the head, indicating the individual was struck from behind, and two of the wounds were to the side and top of the head (left parietal), indicating a blow from above.

Multiple cranial wounds were observed on two females (but no males). These two individuals, Burial 90 and Burial 10, will be discussed in some detail. 


\begin{tabular}{|c|c|c|c|c|c|c|}
\hline Burial & Age & Sex & Bone & Trauma Type & Shape & Status \\
\hline 9.A & MA & M & L frontal & BFT & Point & Healed \\
\hline \begin{tabular}{l|l}
12 & $B$ \\
\end{tabular} & YA & M? & L frontal & BFT & Round & Peri-mortem \\
\hline 72 & YA & $M$ & Frontal/glabella & BFT & Round & Healed \\
\hline 97 & MA & M? & R parietal & BFT & Round & Healed \\
\hline 128 & MA & M? & L parietal & BFT & Ovoid & Healed \\
\hline & & & & & & \\
\hline 10 & YA & $F$ & Frontal/glabella & BFT & Round & Healed \\
\hline 10 & YA & $F$ & L parietal & BFT & Round & Healed \\
\hline 18 & MA & $\mathrm{F}$ & R parietal/occipital & BFT & Round & Healed \\
\hline 68 & MA & $F$ & Frontal/glabella & BFT & Round & Healed \\
\hline 75 & $O A$ & $F$ & L frontal/parietal & BFT & Round? & Healed \\
\hline 90 & MA & $F$ & L parietal & BFT & Round & Healed \\
\hline 90 & MA & $\mathrm{F}$ & R parietal & BFT & Round & Healing \\
\hline 142 & YA & $F$ & $R$ frontal & BFT & Round & Healing \\
\hline 147 & $O A$ & $F$ & L frontal & BFT & Ovoid & Healing \\
\hline $\begin{array}{l}158 \mathrm{~A} \\
\end{array}$ & MA & $\mathrm{F}$ & L parietal & BFT & Round & Healed \\
\hline 168 & MA & $\mathrm{F}$ & L frontal & BFT & Round & Healed \\
\hline & & & & & & \\
\hline 10 & YA & $\mathrm{F}$ & L parietal & SFT (penetrating) & Jagged & Peri-mortem \\
\hline 26 & YA & $\mathrm{F}$ & R frontal & SFT (cut) & Curved & Peri-mortem \\
\hline 52 & YA & $F$ & R frontal & SFT (penetrating) & Jagged & Some-healing \\
\hline 71 & VYA & $F$ & R occipital & SFT (cut/projectile) & Linear & Peri-mortem? \\
\hline 144 A & $O A$ & $F$ & L parietal & SFT (cut/projectile) & Linear & Peri-mortem \\
\hline
\end{tabular}

Table 2. Cranial trauma by burial, age group, sex, bone affected, trauma type, shape of wound, and healing status.

Burial 90, a middle adult female, had two cranial wounds. These were both depression fractures, one on each parietal. These wounds were placed towards the back of the head, and one wound was more completely healed than the other. This indicates that these injuries were incurred from behind and that they happened at two different times. Other than the multiple cranial wounds, nothing appears unusual about this burial. No postcranial traumatic wounds were noted, although she did suffer from DJD (degenerative joint disease) and ante-mortem tooth loss, which were not unusual for adults in this population. She was buried in a fully flexed position with her head to the SE. No associated or burial goods were found with her.

Burial 10, a young adult female, had three cranial wounds. Two depressed fractures, one on the frontal (right on the glabella), and one on the left parietal, were both healed at time of death. A third cranial wound was a penetrating sharp force trauma wound to the top of the left parietal. The excavation photo shows a large projectile point resting on the left parietal. The projectile point, made of Keokuk chert, fits perfectly into the wound and was clearly the cause of death. Unusually, this burial consisted of only a disarticulated skull. Near the cranium was a small pile of human long bone shafts and a large shell gorget. It is unclear if these items are actually associated with the Burial 10 cranium and what this burial of an isolated skull represents. Some possibilities include a trophy, a de-accessioned ancestor, or a group member found after a conflict and brought back "home" for burial. What is clear is that this young woman sustained at least two (possibly three) separate traumatic cranial injuries and that the last one, a projectile blow from above, killed her.

Another type of cranial injury is scalping, and there is some evidence that scalping seems to occur
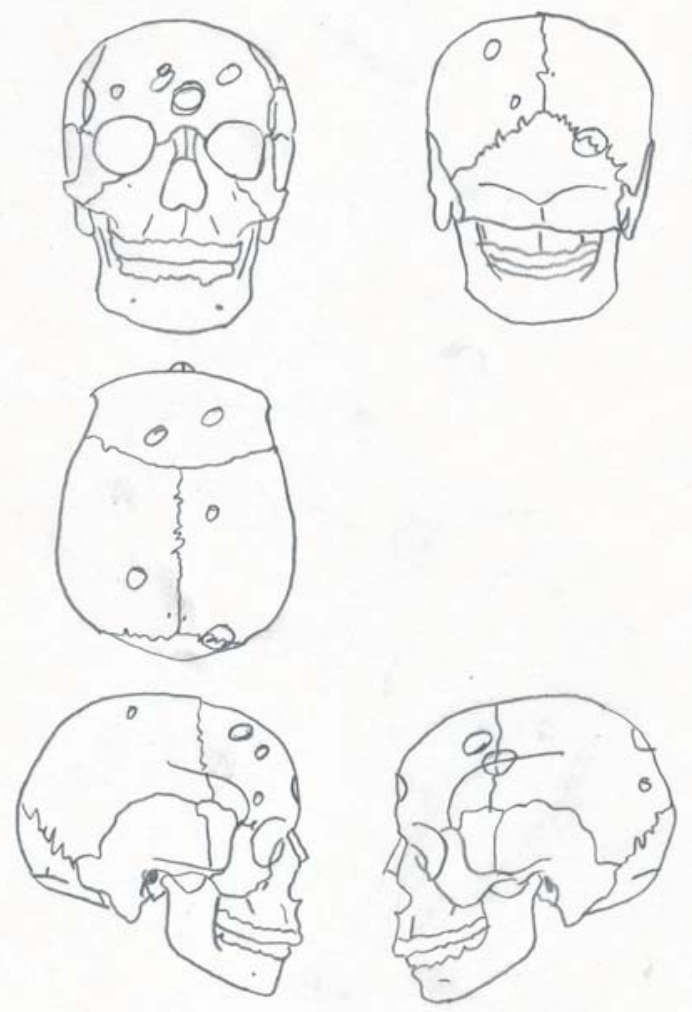

Figure 4. Female, cranial blunt force trauma injuries.

commonly with other signs of trauma or violence (Steadman 2008). There was one possible case of scalping at the Akers site. This was Burial 157, an old adult male. Although Burial 157 had no visible cranial cut marks, the calvarium was strongly reactive with a cap of bony overgrowth in a pattern highly suggestive of scalping. This individual also suffered from osteomyelitis on several other bones, so it is possible that the reactive growth on the calvarium was the result of systemic infection rather that scalping or other head injury. However, it is equally possible that a systemic infection was the result of scalping or other head trauma. As Milner (2005) notes, remodeled bone can obliterate the indicative signs of scalping or other injury. Because no cut marks or other obvious traumatic cranial wounds were visible, this individual is not included in the totals for cranial injury and will not be further discussed.

Although subadults were not included in this study, a previous study found no cranial trauma to subadult remains (Rowe 2009). It should be noted however that there were far fewer subadult remains, and those that were present were in incomplete and quite fragmented. 

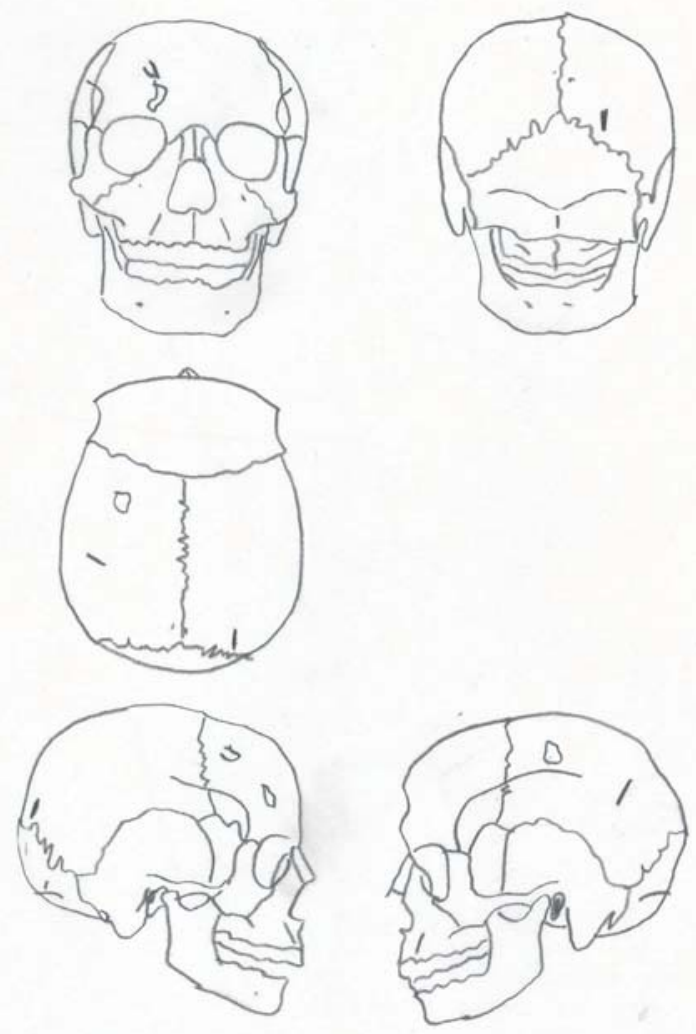

Figure 5. Female, cranial sharp force trauma injuries

\section{Discussion}

Cranial injuries can be caused by falls, accidents, interpersonal violence, or self-inflicted injury (Walker 1989). In modern populations, cranial injuries are relatively rare (Court-Brown and Caesar 2006; Judd 2004, 2008), and in bioarcheological populations, cranial trauma rates are considered to be a good gauge of interpersonal violence (Bogonofsky 2011). In both ancient and modern samples, injuries are most commonly found in adults aged 24-40 years (Judd 2004), and the most common fractures tend to be arm and hand injuries, usually caused by falls (Court-Brown and Caesar 2006; Judd 2004, 2008). A more thorough discussion of the post-cranial injuries to the Akers population can be found in Rowe 2009. Cranial injuries are the focus of this report in attempt to tease out patterns of interpersonal violence. As detailed above, cranial injuries were common at Akers. These results contrast rather sharply not only with what was expected, but with the few previous bioarcheological studies from the Wister Valley.

Despite the well-documented limitations of WPA excavated Wister area Fourche Maline sites (see Schambach 2002), these sites are the largest body of Woodland era data in the Trans-Mississippi South
(Early 2004). The Wister Valley area is considered an appropriate comparison unit for the Akers data not because the sites are all in the same drainage basin, but because previous bioarchaeological studies on Wister Valley populations concluded that the residents shared a common genetic heritage and could be considered a single population (McWilliams 1970, Powell and Rogers 1980, Rose et al. 1983). The conclusion of a shared gene pool allows for assumptions of common resistance and susceptibility, which in turn allows intra-valley comparisons. Furthermore, the geographic proximity of the Fourche Maline Wister Valley sites implies that they shared ecological constraints and resources as well as presumably similar cultural attributes (Rose et al. 1999).

The high rates of cranial injuries at Akers are in stark contrast to other studied Wister Valley sites. At the McCutchan McLaughlin site (34Lt11), a single traumatic fracture was found (Powell and Rogers 1980). Given a total population of 47 , this gives .02 frequency for traumatic fractures (and zero percent for cranial injuries). The combined analysis of the Wann (34Lf27) and Sam (34Lf28) sites found five traumatic fractures (two of these were cranial) out of a total of 105 individuals (McWilliams 1970). This yields .05 frequency for total traumatic fractures and .02 frequency for cranial fractures. These frequencies are not directly comparable to the frequencies noted in Table 1 for the Akers population because the Akers calculations are based on a subset of the population used in the study, while the frequencies calculated for the Sam, Wann, and McCutchan McLaughin sites are based on fractures per total population. To compare, the total number of cranial wounds found at Akers $(n=18)$ was divided by the minimum number of individuals excavated $(\mathrm{N}=227)$. This yields a frequency of .09. The difference between the Sam/Wann cranial injuries and the Akers cranial injuries is statistically significant at $\mathrm{p}=.05$ (twotailed Fisher's Exact Test).

The Akers population then, suffered statistically significant higher rates of cranial trauma, and presumably, interpersonal violence than their neighbors at the McCutchan McLaughlin, Wann, or Sam sites. Additionally, adult males and females at Akers experienced different patterns of cranial wounds. Males experienced cranial trauma as both young and middle adults, but no old adult males were observed with a cranial wound. By contrast, females experienced cranial trauma as young, middle, and old adults. It is noteworthy that old adult females had the highest frequency of cranial trauma (30 percent). Given that no old adult males were observed with cranial trauma, it is not possible to test if this is statistically significant. However, combined with the previously noted observations that only females were observed with SFTs, and that only females were observed with multiple cranial injuries, it seems reasonable to 
conclude that females were more at risk than their male counterparts for experiencing interpersonal violence. These results suggest that individuals at the Akers site (and possibly throughout the Wister Valley) lived a stressful, traumatic, and often violent life, especially adult females.

\section{Conclusions}

Cranial trauma indicates that conflict was clearly a pervasive part of life for the individuals who were buried at the Akers site. Even a few skeletons showing signs of skeletal trauma such as projectile wounds or healed fractures indicates that fighting was probably pervasive and had a noticeable impact on communities (Milner 2005). The patterns of cranial trauma at the Akers site support my previous conclusions that the Wister Valley area was a contested landscape, with extensive feuding resulting in high rates of violent death. The most frequent group to experience cranial injury at Akers was older (50+ years) females. As previously noted, only females were observed with more than one cranial injury, and only females had evidence of SFT wounds. Adult females, particularly older females, appear to have been particularly vulnerable to violence resulting in cranial trauma.

\section{Acknowledgments}

Thank you to the Caddo Nation and the Wichita and Affiliated Tribes for permission to study the burials at the Akers site (34Lf32). Thank you also to the Sam Noble Oklahoma Museum of Natural History where this study was conducted.

\section{References Cited}

Bonogofsky, Michelle

2011 Contextualizing the Human Head: An Introduction. In The Bioarchaeology of the Human Head: Decapitation, Decoration, and Deformation, edited by Michelle Bonogofsky, pp. 1-47. University Press of Florida, Gainsville.

Court-Brown, Charles M., and Ben Caesar

2006 Epidemiology of adult fractures: A review. Injury 37:691-697.

Dye, David H.

2009 War Paths, Peace Paths: An Archaeology of Cooperation and Conflict in Native Eastern North America. AltaMira Press, Lanham, Maryland.
Early, Ann M.

2004 Prehistory of the Western Interior After 500 B.C. In Southeast, edited by Raymond D. Fogelson, pp 560-573. Smithsonian Institution, Washington, D.C.

Galm, Jerry. R.

1984 Arkansas Valley Caddoan Formative: The Wister and Fourche Maline Phases. In Prehistory of Oklahoma, edited by Robert E. Bell, pp. 199-219. Academic Press, New York.

Judd, Margaret A.

2004 Trauma in the City of Kerma: Ancient versus Modern Injury Patterns. International Journal of Osteoarchaeology 14:34-51.

2008 The Parry Problem. Journal of Archaeological Science 35:1658-1666.

Martin, Debra L.

1997 Violence Against Women in the La Plata River Valley (A.D. 1000-1300). In Troubled Times: Violence and Warfare in the Past, edited by Debra L. Martin and David W. Frayer, pp. 45-76. Gordon and Breach Publishers, Newark.

McKern, William C.

1939 The Midwestern Taxonomic Method as an aid to archaeological culture. American Antiquity 4(4):301-313.

McWilliams, K. Richard

1970 Physical Anthropology of Wann and Sam: Two Fourche Maline Focus Archaic Sites in Eastern Oklahoma. Bulletin of the Oklahoma Anthropological Society 19:101-136.

Milner, George R.

1999 Warfare in Prehistoric and Early Historic North America. Journal of Archaeological Research 7(2):105-151.

2005 Nineteenth Century Arrow Wounds and Perceptions of Prehistoric Warfare. American Antiquity 70(1):144-156.

Newkumet, Phil J.

1941 Quarterly Report - LeFlore County Unit, September 1941. In LeFlore County Archaeological Project. Manuscript on file, Western History Collection, University of Oklahoma, Norman Oklahoma. 
Ortner, Donald J.

2003 Identification of Pathological Conditions in Human Skeletal Material. Academic Press, New York.

Powell, Mary Lucas, and J. Daniel Rogers

1980 The Bioarchaeology of the McCutchanMcLaughlin Site (34Lt-11): Biophysical and Mortuary Variability in Eastern Oklahoma. Studies in Oklahoma's Past No. 5. Oklahoma Archeological Survey, Norman.

Rogers, J. Daniel

1978 Federally sponsored Archaeological Work in Oklahoma before WWII. Unpublished manuscript, University of Oklahoma, Norman Oklahoma.

Rose Jerome C., Murray K. Marks, and Earl Riddick 1983 Bioarchaeology of the Bug Hill Site. In Bug Hill: Excavation of a Multicomponent Midden Mound in the Jackfork Valley Southeast Oklahoma, by Jeffery H. Altschul, pp. 241-278. Report of Investigation No. 81-1. New World Research, Inc., Pollock, Louisiana.

Rowe, Simone B.

2009 The Akers Site (34Lf32): Preliminary Bioarchaeology of a Fourche Maline Site. Master's thesis, Department of Anthropology, University of Oklahoma, Norman.

2014 Wister Area Fourche Maline: A Contested Landscape. Ph.D. dissertation, Department of Anthropology, University of Oklahoma, Norman.

Schambach, Frank F.

1982 An Outline of Fourche Maline Culture in Southwest Arkansas. In Arkansas Archeology in Review, edited by Neal L. Trubowitz and Marvin D. Jeter, pp. 132-197. Research Series No. 15. Arkansas Archeological Survey, Fayetteville.
1998 Pre-Caddoan Cultures of the Trans-Mississippi South. Research Series 53. Arkansas Archeological Survey, Fayetteville.

2002 Fourche Maline: A Woodland Period Culture of the Trans-Mississippi South. In The Woodland Southeast, edited by David G. Anderson and Robert C. Mainfort, Jr., pp. 91-112. University of Alabama Press, Tuscaloosa.

Steadman, Dawnie Wolfe

2008 Warfare Related Trauma at Orendorf, A Middle Mississippian Site in West-Central Illinois. American Journal of Physical Anthropology 136(1):51-64.

Tung, Tiffany

2008 Dismembering Bodies for Display: A Bioarchaeological Study of Trophy Heads from the Wari Site of Conchopata, Peru. American Journal of Physical Anthropology 136(3):294-308.

Walker, Phillip L.

1989 Cranial Injuries as Evidence of Violence in Prehistoric Southern California. American Journal of Physical Anthropology 80(3):313-323.

Willey, Gordon R., and Phillip Phillips 1958 Method and Theory in American Archaeology. University of Chicago Press, Chicago. 